\title{
MAMACITA FALA, VAGABUNDO SENTA: ARTIVISMO, CONSTRUÇÃO IDENTITÁRIA E RESISTÊNCIA EM KAROL CONKA
}

\section{MAMACITA SPEAKS, GOOD-FOR-NOTHING SITS: ARTIVISM, IDENTITY CONSTRUCTION AND RESISTANCE IN KAROL CONKA}

\author{
Ricardo Afonso-Rocha ${ }^{1}$ \\ Iago Moura Melo ${ }^{2}$ \\ Celina Rosa dos Santos $^{3}$
}

\begin{abstract}
Resumo: neste trabalho, analisamos as letras de quatro canções da rapper Karol Conka, enquanto fenômeno de socialidade. O nosso objetivo é identificar, nessas músicas, elementos político-estéticos de notação contra-hegemônica. Como aporte teórico, os estudos sociológicos de Michel Maffesoli são tomados como instrumento de compreensão dos processos dinâmicos de construção identitária. Sugerimos, então, que a poética da rapper, nessas canções, possui perfil artivista, já que tensiona a norma estética padrão centrada no masculino, branco, cristão, burguês. A relevância teórica da pesquisa decorre do imperativo analítico de se compreender a estetização da vida como fenômeno de socialidade da mulher negra e periférica. A pertinência prática exterioriza-se na inevitabilidade, no contexto atual de popularização de discursos de ódio, da circulação de estudos contra-canônicos, como meios efetivos e afetivos de contestação e resistência. Para esta pesquisa, foram examinadas as músicas Tombei, É o poder, Lalá e Gandaia por serem mais emblemáticas para o presente estudo.
\end{abstract}

Palavras-chave: (est)ética; sociabilidade; discurso de resistência; artivismo negro.

Abstract: in this work, we analyze the lyrics of four songs by rapper Karol Conka as a phenomenon of sociality. Our goal is to identify, in these songs, political-aesthetic elements of counter-hegemonic notation. As a theoretical contribution, the sociological studies of Michel Maffesoli are taken as an instrument of understanding the dynamic processes of identity construction. We suggest, then, that the rapper's poetics, in these songs, has an artivist profile, that is, it stresses the standard esthetic norm centered on the masculine, white, Christian, bourgeois. The theoretical relevance of the research stems from the analytical imperative of understanding the aestheticization of life as a phenomenon of sociality of black and peripheral women. The practical pertinence is expressed in the inevitability, in the current context of popularization of discourses of hatred, of the circulation of counter-canonical studies, as effective and affective means of contestation and resistance. For this research, the songs

\footnotetext{
${ }^{1}$ Mestrando em Letras: linguagens e representações (PPGLLR/UESC). Bacharel em Direito (UESC) e Advogado (OAB/BA). Membro do Grupo de Estudos O Espaço biográfico no horizonte da literatura homoerótica (GPBIOH). Bolsista da Fundação de Amparo à Pesquisa do Estado da Bahia (FAPESB). http://orcid.org/00000001-5873-4136. E-mail: rickwhoop22@ gmail.com

${ }^{2}$ Doutorando em Letras pela Universidade Estadual de Santa Cruz (UESC). Mestre em Letras (UESC). Bacharel em Direito (UESC) e Advogado (OAB/BA). É membro do Grupo de Estudos Discursivos (GED/UESC), do Grupo de Estudos Pecheutianos (GEP) e do Coletivo Contradit (Coletivo de Trabalho - Discurso e Transformação). Bolsista da Coordenação de Aperfeiçoamento de Pessoal de Nível Superior (CAPES). ORCID: http://orcid.org/0000-0003-2144-0948.

${ }^{3}$ Mestranda em Educação e contemporaneidade na Universidade do Estado da Bahia (UNEB). Professora do Instituto Federal da Bahia, Campus Ilhéus. Graduada em Ciências Sociais e especialista em História Social e Política do Brasil e do Espírito Santo pela Universidade Federal do Espírito Santo.

ORCID: https://orcid.org/0000-0002-4047-2067
} 
Tombei, É poder, Lalá and Gandaia were examined for being more emblematic for the present study

Keywords: (aesth)etics; sociability; resistance speech; black artivism.

\section{Introdução}

A poética ${ }^{4}$ de Karol Conka é acontecimental. Enquanto discurso, não se dá à revelia do sócio-histórico, do ideológico e de outros discursos, já que os gêneros de discurso significam a partir do todo enunciativo em que se inserem (BAKHTIN, 1992). Por isso, a obra da rapper se dá a partir de um horizonte de retrospecção (AUROUX, 2008), isto é, o conjunto de saberes que lhe são antecedentes, mas que afetam a produção/constituição de seu dizer. Não há sujeito, senão sujeito no discurso e na linguagem, não havendo que se falar também em discurso fundador (ORLANDI, 1993). Assim, inicialmente, é necessário se ter em conta a historicidade do dizer, isto é, do discurso, e do sujeito, enquanto posição que assume nesse dizer e num dado contexto ideológico, de modo a se poder assegurar o seu potencial de prospecção, ou, no dizer de Bakhtin (1992), para que haja projeção de sentido que resulte na formação de compreensões responsivas ativas 5 .

Karol Conka enraíza sua poética como horizonte do futuro, que não só remete a outros discursos dispersos no tempo, mas que se finca como uma possibilidade de reinterpretar o passado para projetar-se para o porvir, antecipando-o. A luta por reconhecimento ${ }^{6}$ e a denúncia social, ecoadas em composições como Tombei, É o poder, Lalá e Gandaia, promovem rasuras nas estruturas discursivas de poder, potencializando o acontecimento e sequestrando a fala dos lugares enunciativos tradicionais, condicionados por regimes de verdade (FOUCAULT, 2012). Por essa razão, este trabalho se vale das composições da rapper para promover o debate e a crítica, indicando a mudança e a tensão na retórica do poder, sem pretender, contudo, sair dela;

\footnotetext{
${ }^{4}$ Aqui, tem-se em conta o sentido aristotélico do termo poiesis, cujo referente se constitui por todo tipo de criação, isto é, arte, como gênero, sendo a música uma de suas espécies (ABBAGNANO, 2007). Esse é o sentido implementado nesta pesquisa. Será desconsiderado, nessa análise, elementos estritamente musicais como melodia, arranjo, cifras, etc. Abordaremos, tão somente, as letras das canções, tomadas, dessa forma, como poemas.

${ }^{5}$ Bakhtin (1992) propõe se considerar o interlocutor como muito mais que mero destinatário passivo de um discurso. O interlocutor é um falante e não mero destinatário de um processo comunicativo estático, de modo que a compreensão do enunciado nunca se engessa na teoria, mas sempre implica uma prática, isto é, uma resposta ativa, seja ela imediata ou mediata, fincada na interação verbal. Este trabalho traduz uma compreensão responsiva ativa às composições de Conka, constituindo-se, de igual modo, como elo na cadeia enunciativa, e, portanto, passível de diálogos ulteriores.

${ }^{6}$ A respeito da noção de reconhecimento consultar FRASER, Nancy; HONNETH, Axel. ¿Redistribución o reconocimiento?: un debate político-filosófico. [S.L]: Fundación Paideia Galiza, 2006.
} 
afinal, como bem desenhou Foucault (2017), as relações de poder são microfísicas, no sentido de não serem localizáveis, em uma estrutura específica, e de serem móveis. O poder está distribuído, de forma dispersa, nas malhas sociais, de modo que não é possível supor um "estado de fora" em relação a ele.

Entendemos a estetização negra, erótica e feminista, presentes nas músicas da rapper Karol Conka, enquanto fenômeno de socialidade, o que implica perceber que essa estética confessa um ethos constituído a partir de emoções e afetos com-penetrados; parte de uma experiência de transexistência, enquanto um modo de existir para além do padrão hegemônico branco-cis-hétero-masculino - esse último, perpetuado pelo conservadorismo inscrito em valores universalizantes.

Nesse sentido, afirmamos que o estético (que inevitavelmente sempre é político) em Conka, constitui-se como prática de resistência, ecoa saberes/discursos ausentes e negligenciados, em oposição ao moralismo intelectual da razão abstrata e violenta (MAFFESOLI, 2015).

A poética de Conka expressa experiências de transexistência e reexistência à docilização dos corpos, num movimento de contestação, intrincado nas relações sociais e, inevitavelmente, na luta de classes. No que concerne aos processos tradicionais de estetização, a construção da arte se dá sob a égide dos valores hegemônicos, na medida em que intenciona o cânone. Nesse sentido, o rap emerge como um novo tipo de estética, que rasura as relações hegemônicas de poder e refuta territórios de ficção impostos como realidade única e global. O rap, no atual cenário de enfrentamento das políticas de subalternização legadas pela modernidade ocidentalocêntrica, engendra práticas de luta, no seio do discurso, de elevado potencial subversivo. São consideradas as singularidades da linguagem escrita e inscrita no universo do rap: um conjunto de práticas sociais, cujos modos de funcionamento afetam as formas de construção identitária e as relações de poder que as determinam. Isso é feito a partir do desempenho de um papel histórico de criação, ressignificação e reinvenção de usos sociais da linguagem.

A relevância teórica desta pesquisa decorre do imperativo analítico de se compreender a estetização da vida na língua e na música, como fenômeno de socialidade num contexto de construção identitária. Conforme consultas realizadas nas bases SciELO, Sucupira e Google Acadêmico, ao tempo da elaboração desta pesquisa, são inexistentes trabalhos acadêmicos que contemplem a poética de Karol Conka, tampouco que a observem sob as lentes da resistência, 
do poder e da estética. A pertinência prática exterioriza-se na inevitabilidade de, no contexto atual de popularização de discursos de ódio, fazerem-se circular estudos contra-hegemônicos, como meios efetivos e afetivos de exercício do direito de resistência e de contestação (BOBBIO, 2004), em reforço ao imperativo de democracia cultural.

Somos partidários do pluralismo metódico (FEYERABEND, 2007). O monismo está muito afeito ao ideal prometeico de episteme, que decorre da ciência moderna ocidentalocêntrica. A atitude monista vela sempre possibilidades outras de o fenômeno se mostrar, já que parece ignorar a sua complexidade. No seio dessa opção, ecoa a compreensão conforme o que a verdade de uma coisa é e não é, simultaneamente, isto é, "a essência do universo é a contradição" (MAFFESOLI, 2004, p. 126). O pluralismo é, assim, a opção pela conjugação de diferentes métodos e conceitos, para que o fato cognoscível se dê de modo menos precário e parcial, isto é, para que possa se dar enquanto processo engendrado por práticas materiais. Essa intuição de pesquisa se harmoniza com a complexidade das sociedades contemporâneas, tendo por base as críticas feitas à metafísica e à ideologia.

Inicialmente, expomos alguns aspectos biográficos a respeito de Karol Conka, de maneira a se colocar a reflexão sobre a construção de sua subjetividade a partir de um horizonte sócio-histórico. Também, é observado o perfil estético do rap e a sua importância como ferramenta de luta por reconhecimento. Em seguida, examinamos excertos das letras Tombei, É o poder, Lalá e Gandaia, para que as inferências feitas acerca da poética de Conka encontrem um referente em que possam se respaldar.

\section{Da tomada de um espaço enunciativo à subversão pelo gênero rap}

Negra, periférica, bissexual, de origem humilde e feminista, Karoline dos Santos Oliveira (Karol Conka), nasceu em Curitiba no dia $1^{\circ}$ de janeiro de 1987. Desde criança escrevia canções e sonhava em ser cantora, "eu brincava de ser uma das Spice Girls no espelho, me montava toda" (CONKA, 2017b). Aos 16 anos, liga-se ao rap quando participa de um festival de poesia na escola. A esse respeito, comenta: "Fiz uma poesia e, quando li no palco, disseram que era música, que era rap. Naquela hora, decidi o que queria ser quando crescer" (CONKA, 2016). 
Conka revela, em entrevistas, que sofreu preconceitos desde a infância, inclusive na escola, por parte de alguns de seus professores, e que, infelizmente, pouca coisa mudou com relação aos dias de hoje:

Aos 9 anos, um coleguinha da escola disse que só falaria comigo quando eu fosse branca. Quando cheguei em casa, coloquei minha mão em um balde com água sanitária, porque via minha mãe clareando os panos de chão daquele jeito. Meus pais perceberam o que eu tinha feito e me explicaram que as pessoas que me achavam feia e me chamavam de macaca tinham problemas de visão. Que eu era linda, que eles me amavam exatamente como eu era e que, principalmente, eu deveria me amar. Desde então, não me deixei mais abalar por isso. Não quero contar história triste ou bancar a vítima, como dizem por aí, mas as pessoas precisam entender que o preconceito machuca e deixa marcas profundas na gente. (CONKA, 2016).

No ano de 2013, Conka lança seu primeiro álbum Batuk Freak, com o qual venceu a categoria artista revelação do prêmio Multishow de música brasileira. O sucesso de fato aconteceu em 2014 com a música Tombei, que levou a cantora ao reconhecimento nacional. Assim, consagrada pelo público como um dos grandes nomes femininos do rap, Karol Conka participa de importantes festivais de músicas como o Lollapalooza, em 2016. No mesmo ano, cantou na abertura dos Jogos Olímpicos no Rio de Janeiro. Em março de 2017, assumiu o comando do programa "Superbonita" do canal GNT, anteriormente apresentado por Ivete Sangalo.

Assumidamente bissexual, a rapper é a(r)tivista dos movimentos negro e feminista, sendo reconhecida por suas músicas de resistência, por fazer ecoar vozes que foram historicamente silenciadas e alvo de subalternização cultural. De suas apresentações, destacamse a performance artística e discurso de emancipação destinado a mulheres, negros e LGBT+:

Já sabia que seria xingada e que o meu trabalho seria visto com indiferença só porque sou uma menina. Mas mostrei que minha música é séria, que não estava brincando quando dizia que ali era o meu lugar. Falava com todo mundo de igual para igual. Assim, aos poucos, fui ganhando meu espaço e o respeito dos outros músicos. (CONKA, 2016).

Conka milita como voz ativa contra o preconceito em diversas de suas facetas principalmente pelo seu não enquadramento no padrão hegemônico imposto. "Esses machistas só respeitam a mulher depois que ela ganha mais do que eles, quando ela fica mais famosa do que eles. Eu estou pau a pau com os famosos do rap. Agora, eles têm que sentar quando eu falo" (Grifo nosso) (CONKA, 2017b). 
Para Bentes (2017), Conka representa as meninas pretas do rap e do pop que vêm construindo outras expressões políticas, um outro feminismo ao expor "seus corpos de maneira ativa, muitas vezes escandalosa, falando de desejo, sexualidade, multi parceiros, posições sexuais, motel, masturbação, corpo gordo, celulite, beleza negra, sexo anal, oral, sexismo, patriarcalismo, gozo, de forma explícita e desencanada”. Nesse sentido, a fala da rapper resiste à castração simbólica do seu corpo, festeja a sua liberdade sexual e a conquista.

Matos (2010) comenta que, a partir do ano 2000, há, no Brasil e na América Latina, expressões de um outro movimento feminista, a que denomina quarta onda. A quarta onda feminista é marcada pela visão pós-neoliberal e anti-economicista, dando ênfase às dimensões políticas da justiça social. Há a valorização das formas femininas de existência e resistência ao capitalismo, ao machismo e ao racismo, numa articulação horizontalizada que "busca por uma democracia efetivamente participativa, militando por uma nova forma de organização do poder político, que subordine a burocracia ao empoderamento dos cidadãos e das cidadãs" (MATOS, 2010).

O feminismo negro da rapper Conka enquadra-se na quarta onda do movimento feminista, a que alude Matos (2010), especificamente no que diz respeito à inserção de mulheres negras e periféricas na reivindicação de direitos ${ }^{7}$. Assim, compreendendo que seus atos, comportamentos e corpo são políticos, logo uma forma de transmitir o que pensa, Conka afirma:

Moda é uma forma de expressão, de transmitir o que penso para as pessoas. Vemos poucas mulheres negras, pobres, gordas, gays, da periferia representando a gente na mídia. Para mim, é muito importante representar essas mulheres. Alcançar meus sonhos e mostrar que a gente pode, sim, ser bonita, gostosa e vestir o que nos faz feliz. Que a gente quer nosso espaço, que a gente quer falar de sexo e de amor, ou só de sexo. Que temos o poder e, para mim, poder é amor próprio e aceitação. (2017b)

A moda é, assim, tomada por Conka como uma forma de expressão, de resistência e de existência; de autorrepresentação, com ênfase na desconstrução de sentidos gregários que algumas peças do vestuário geram (sapatos, óculos, roupas íntimas) e na construção de um sentimento compartilhado de identificação. Tomando por base o que nos diz Hall (2004),

\footnotetext{
7 "Multiplicaram-se, então, as modalidades de organizações e identidades feministas. As mulheres pobres articuladas nos bairros por meio das associações de moradores, as operárias por meio dos departamentos femininos de seus sindicatos e centrais sindicais, as trabalhadoras rurais por meio de suas várias organizações começaram a se identificar com o feminismo, o chamado feminismo popular. As organizações feministas de mulheres negras seguiram crescendo e ampliando a agenda política feminista e os parâmetros da própria luta feminista. Esse crescimento do feminismo popular trouxe, como conseqüência fundamental, um pouco da diluição das barreiras e resistências ideológicas em relação ao feminismo" (Grifos nossos) (MATOS, 2010).
} 
concebemos essas técnicas de si enquanto gestos múltiplos de identificação, em que se engaja o processo identitário da rapper, a qual não possui uma identidade enquanto presença teoteleológica, mas imprime seu ego-a-construir em sua fala subversiva profanando o estável no imaginário, em rejeição à moldura identitária que lhe é imposta pelo Sujeito Universal.

Em sentido parecido, Maffesoli (2010) vê a moda como uma forma de produção de imagens que participam da organização da sociabilidade de uma tribo, numa dimensão nãoracional (isso não quer dizer irracional), da ordem da paixão, das emoções e dos afetos. A tribo é, assim, traduzida por um sentimento de estar-junto a partir do compartilhamento de sentimentos, isto é, da vivência, em conjunto, de emoções. Há, nesse momento, um deslocamento do ideal de indivíduo para a realidade da pessoa. A pessoa enquanto um plural (“eu sou os outros”) de identificações múltiplas, é o "instante eterno", o presente vivido cuja consequência da pluralização é a multiplicação das emoções compartilhadas (MAFFESOLI, 2005). A moda, então, é expressão do retorno a Dionísio pela celebração hedonista da existência, do corpo, da intensidade, do sensível. Nesse sentido, a moda se torna um lugar de representação/apresentação do eu e do outro, da tribo, das múltiplas identificações, personas ou máscaras, mas nunca de apresentação de identidades fixas/fictas.

Em Maffesoli (1988;1999), a estética está irremediavelmente atrelada aos afetos. O autor sustenta que o conceito de estética, característico da modernidade, assume o drama como caminho para chegar à verdade. Estatiza-se a verdade, enquanto veritas (adequação entre linguagem e realidade, ou entre intelecto e coisa), como paranoia, que do grego significa "o pensamento que vem de cima". Maffesoli propõe pensar, de outra perspectiva, o estético como noção, e não como conceito, em culto ao trágico, marcada pela metanóia, isto é, por um pensar que acompanha a realidade, sem criá-la. A realidade é constituída na linguagem. A verdade do/no estético é, portanto, do discurso, linguisticamente construída. Mas, frisamos, o real da existência, em nosso modo de ver, que não se confunde com o imaginário da realidade produzido pela ideologia, insiste, não cessa, é o impossível do simbólico.

Nesse passo, por ativismo musical se deverá entender todo o processo contínuo de (trans)formação cultural. Não se trata de ser, de uma ontologia, mas de um tornar-se, isto é, é um processo pelo qual o artista vivencia o viver-com-os-outros-no-mundo, o estar-junto. Em Conka, esse ativismo assume o cariz de resistência e reexistência, uma vez que promove a discussão da ordem posta e a subversão dos valores hegemônicos, a partir da estética do/no discurso. Nessa esteira, Nina Simone, uma das mais importantes vozes na luta dos direitos dos 
negros na década de 1960, quando questionada sobre o perfil político das suas canções, responde:

O dever de um artista, pelo menos com a minha preocupação, é o de refletir os tempos [...] eu escolhi refletir os tempos e as situações nas quais me encontro [...] eu acho que é impossível você não se envolver [...] eu acho que não há escolhas. Como você pode ser um artista e não refletir os tempos? Para mim, essa é a definição de um artista. (Grifos nossos) (SIMONE, 2015).

É inegável que, dentre os ritmos contemporâneos, o rap é um dos que mais refletem os tempos. As/os rappers utilizam-se da poesia, do ritmo e das batidas para retratar as realidades em que vivem. Normalmente, esses artistas são originários de comunidades periféricas negras, cuja atuação governamental é lacunosa, pesando sobre essas populações a falta de políticas públicas, o que se desdobra em exclusão social e preconceito por parte daqueles que vivem no centro da sociedade. No rap, então, presentam-se as denúncias contra as injustiças sociais latentes, das violências identitárias, sexistas e epistêmicas, que funcionam a partir do que Orlandi (1993) denomina silenciamentos constitutivos e locais, seja por parte da mídia, dos setores públicos, e da sociedade amplamente considerada. É nesse sentido que o rap pode se tornar uma ferramenta política e subversiva na luta por direitos de minoria.

Nesse seguimento de ideias, entendemos adequado, portanto, o emprego do termo artivismo, conforme o emprega Baigorri (2003), para designar o hibridismo que funciona nas práticas discursivas artísticas, dentre elas o rap, as quais se engajam, política e culturalmente, na denúncia de hierarquias sociais, resistindo e assinalando contradições de classe, gênero, sexualidade, dentre outros regimes de opressão que opera sobre os sujeitos.

A partir da década de 1970, comparecem, nas canções, temas como sexualidade, sexo, prazer, amor livre, liberdade sexual, gozo, sexo anal, sexo oral, múltiplos parceiros, aborto, liberdade sexual, dentre outros temas relacionados às experiências feministas, numa dimensão vaginal, em superação ao falo-logo-centrismo moderno. Esses sentidos moralmente subversivos vêm, assim, atravessar a discursividade do rap, de modo a fortalecer o seu potencial artivista, performativo, revolucionário, atuante na construção de uma identidade negra e feminina politicamente engajada num projeto de transvaloração de valores hegemônicos, provenientes de colonialidades de saber (MIGNOLO, 2003) e de poder (QUIJANO, 2005).

O rap nacional contempla, em sua historicidade, mulheres que, desde atitudes contracanônicas, fizeram de suas músicas expressões e lugares de resistência contra o machismo, o sexismo e demais regimes de poder. Nesse sentido, as mulheres negras vêm marcar o rap 
brasileiro, ao reivindicar o espaço que lhes foi negado, pautas até então negligenciadas, inclusive por cantoras e artistas brancas, fazendo das suas composições expressões de resistência e de luta. Essas músicas traduzem formas de resistir, mas também se materializam enquanto formas de existir para além da construção das identidades-norma. Contesta-se, assim, por meio dessas discursividades, ao lado de outras, a produção cultural hegemônica e os sistemas de silenciamento e exclusão que negam às notações culturais que divergem do padrão estético imposto (pressuposto) o valor de objeto artístico.

As mulheres negras, rappers, entendem o papel emancipador que têm suas canções. Elas veem a música como expressão e experiência de resistência, existência e reivindicação e, nesse sentido, desenham e articulam suas estratégias discursivas para minar os processos de subalternização que as afetam. Uma dessas estratégias pode ser a, por nós denominada, poética do desmascaramento, pelo que os versos cantados são agenciados por políticas de resistência, que, ao revés de cantar a igualdade, cantam a diferença e a violência, de modo a denunciá-las, o que, mais uma vez, aponta para uma discursividade artivista. Veja-se um trecho da música Mulheres Negras, da rapper Yzalú, a esse respeito:

\footnotetext{
Enquanto mulheres convencionais lutam contra o machismo As negras duelam pra vencer o machismo, o preconceito, o racismo Lutam pra reverter o processo de aniquilação Que encarcera afrodescendentes em cubículos na prisão Não existe lei maria da penha que nos proteja Da violência de nos submeter aos cargos de limpeza De ler nos banheiros das faculdades hitleristas Fora macacos cotistas
}

A partir desse trecho, é possível inferir que o rap feminino negro, ou pelo menos parcela dele, constitui-se como uma estética de resistência, visto que representa a subversão de tropos discursivos hegemônicos, já que transcende colonialidades de saber e poder, bem como outros regimes de opressão a partir de escritas de si e do outro, tendo perfil de denúncia social engajada (artivismo) em evidenciar processos assimétricos de subalternização. Mulheres negras lésbicas, trans, bi, travestis, gordas, não-binárias, queer, transviadas, sapatões, masculinizadas, abjeções etc., através do rap, trazem luz às suas experiências de resistência e luta contra o machismo, o sexismo, o racismo e contra as repressões morais, políticas e religiosas às dissidências sexuais e de gênero. Essas mulheres se utilizam das suas performances artísticas e musicais para tensionar a construção social do gênero e os padrões identitários ditados pelo Outro. 
O rap nacional, tido enquanto espaço desses artivismos, aborda assuntos que despertam o interesse das mulheres e de elevada visibilidade, como legalização do aborto, autoestima, machismo, igualdade de gênero, feminicídio, sexualização da mulher, racismo. Tensiona-se, assim, as identidades fixas/fictas a partir da subversão do normal, pelo que são deslocadas e descolocadas as relações de poder estabelecidas pela cultura hegemônica, "[...] fazendo surgir novas identidades e fragmentando o indivíduo moderno" (HALL, 2004, p. 8).

Artistas como Dina Di, Lady Chris, Nega Gizza, Negra Li, Karol Conka, Preta Rara, Yzalú, MC Soffia fizeram e fazem do rap um gênero musical de articulação política, social e sexual, de luta contra opressões. Ao tensionar as relações de poder estabelecidas pela cultura hegemônica, branca, masculina, cis e hétero, essas artistas fazem do rap um gênero musical de expressões dos múltiplos feminismos e negritudes.

Nesse caminhar, é alegórica a frase de Dina Di (2002), no curta-metragem Guerreiras do Rap:

[...] eu escolhi isso como uma maneira de eu sobreviver daquilo que eu gosto de fazer que é expor a realidade que eu vivo, falar sobre a minha realidade, sobre a realidade de várias minas aí, que eu vejo aí no dia a dia. É importante falar da mulher. Os homens já têm os homens para falar, a gente tem que falar de nós.

Nesse mesmo curta-metragem, Negra Li afirma que há um mito construído e reforçado pela mídia e pelo mercado de que o rap é “coisa de homem", porém, enfatiza que nos últimos anos houve uma grande mudança no cenário nacional com forte participação das mulheres, especificamente das mulheres negras, fala em que ressoa os processos discursivos em que se engaja uma quarta onda feminista, nos termos a que alude Matos (2010).

Assim, percebe-se que a matriz discursiva do rap transforma-se quando ele é protagonizado por mulheres, ocorrendo uma reestruturação de valores morais e sexuais e de valores atribuídos às categorias de gênero. Quando protagonizado por mulheres negras, há uma revolução na matriz discursiva que promove uma reordenação de valores na intersecção gênero e raça, com claro recorte de classe. Logo, o discurso do rap passa a vincular-se a uma multiplicidade de vozes clandestinas: mulheres, negras, LGBT+, periféricas, gordas etc., constituindo discursividade de expressão contra-canônica.

Conforme Ribeiro (2015), pode-se identificar, como o tema central do feminismo negro, o legado da luta, haja vista que todas as mulheres negras compartilham a comum experiência 
de comporem uma sociedade que as desprivilegia. A mulher negra, assim, luta contra violências simbólicas e históricas, de modo que suas composições no rap transformam-se em bandeira musicada, suas letras carregam uma duplicidade erótico-política que desnuda e oblitera seu assujeitamento.

Com efeito, o foco do feminismo negro, cuja estética encontra-se presente nas músicas de Karol Conka, conforme demonstraremos a seguir, é pensar a intersecção das desigualdades na qual uma única pessoa, a depender de suas características, pode se encontrar. "Assim, o elemento representativo das experiências das diferentes formas de ser mulher estaria assentado no entrecruzamento entre gênero, raça, classe, geração sem predominância de algum elemento sobre o outro". (RIBEIRO, 2015).

A rapper negra Yzalú ressalta a importância do ativismo musical na intersecção entre gênero, raça e classe: "quando você nasce mulher negra, você tem mais um percentual de não dar certo e aí vai de você mudar esse curso ou não. E eu vejo que Mulheres Negras retrata[m] exatamente esses empecilhos que envolvem a questão da mulher negra. A arte anda junto com o ativismo" (GUERREIRAS..., 2014).

As estéticas negras, feministas e eróticas são ${ }^{8}$, em si, estéticas de resistências que se opõem à excessiva formalização, ao dualismo esquemático e à razão instrumental, rompendo, assim, com a referência única - o homem, branco, heterossexual - para questionarem sobre a diferença na multiplicidade, a partir de múltiplas identificações. Põe-se uma ética das estéticas indesejadas (MAFFESOLI, 1998), associada à rebeldia por não se reproduzirem valores morais da "família nuclear burguesa". Fala-se o proibido, questiona-se, reivindica-se. Os artivismos musicais negros e feministas operam, portanto, deslocamentos da homogeneidade idealizada para a realidade em sua heterogeneidade, derrubando a ficção/fixão da referência única.

Entretanto, não se pode ignorar que "[...]preciso me sujeitar às normas sociais com seus quadros identitários estabelecidos para ser reconhecido como sujeito. Mas posso também sentir que os termos pelos quais sou reconhecido fazem da vida algo impossível a se viver" (SAFATLE, 2014). Note-se como tal colocação alude às expressões de resistência aos padrões

\footnotetext{
${ }^{8}$ Maffesoli propõe uma visão de mundo marcada pela sensibilidade, pela eroticidade. Assim, defende o resgate das dimensões sensíveis das experîencias humanas. Afirma que "É estando desapegado em relação aos diversos ideais impositivos e universais, é estando enraizado no ordinário, que o conhecimento responde melhor à sua vocação: a libido sciendi. Por que não dizer: um saber erótico que ama o mundo que descreve. Assim, pela purgação do geral, da verdade, daquilo que é tido como correto, pode encarar-se o plausível e os possíveis das situações humanas" (1998, p.14).
} 
hegemônicos e permite ler a resistência que funciona imanente aos quadrantes do poder, pela subversão.

Karol Conka comparece, enquanto voz subversiva, assim, num contexto de construção de identidades desviantes, questionadoras e desacreditadas com as categorias sociais e estruturas imutáveis de sujeito. Identidades desestabilizadoras, que desestruturam antigos alicerces, seus valores e suas crenças a partir e pelos entrelugares da linguagem e da cultura (BHABHA, 2013). Denuncia-se a saturação do indivíduo, da nação, da epistemologia ocidentalocêntrica, a partir dos movimentos polissêmicos que contemplam os dados mundanos, o vívido e o agora, o instante eterno (MAFFESOLI, 2010). As músicas de Conka comemoram, portanto, a reversibilidade, o "tudo vale" de Feyerabend ou o "saber relativista", de que nos fala Maffesoli, embora cumpra esse saber um papel engajado com o real da existência, vez que desnuda a Identidade pela Diferença.

Para Maffesoli $(1988 ; 1999 ; 2004 ; 2005 ; 2010)$, o pensamento moderno ocidental é marcado pela unicidade, separação e distância. Isso porque ignora a polissemia do dado mundano, reduzindo-a a um único valor (de matriz judaico-cristã), desmembrando o ser humano da natureza, distanciando-se da ebulição real da vida que fervilha em múltiplas identificações, castrando o gozo na pluralidade do Eu. Esse pensamento, sustenta Maffesoli, traduz-se numa ontologia - una, estável, transcendente. A ontologia translada a primazia de um “Ser intangível: seja ele Deus ou o Indivíduo, aos quais poderíamos acrescentar a nação-Estado, as instituições valorizadas pela modernidade, em suma, toda entidade que tenha uma identidade estável e bem definida" (MAFFESOLI, 2004, p. 98). A estética, nessa esteira, provoca um resvalar da ontologia para a ontogênese. Em Maffesoli (2004), a ontogênese seria a alternativa à ontologia, pois esta seria uma virada linguística, um pensamento metanóico, ao invés de identidades fragmentadas, teríamos processos de identificações plurais: O político refigura-se no estético e reinventa o ético pelo si.

A ontogênese, por sua vez, é mais flexível, mais fluida. Ela insiste em estados sucessivos - eu diria, em identificações múltiplas. Cada uma delas sendo real em um tempo T, mas tornando-se mais porosa e mesmo evanescente em um tempo T1, T2. Como se vê, a ênfase no devir, na dinâmica do Ser, dá conta da impermanência das situações, das entidades pessoais e, ao mesmo tempo, da perduração da vida como tal. (MAFFESOLI, 2004, p. 99).

O artivismo, em Conka, abre espaços para identificações assimétricas, antepredicativas e não hegemônicas, destituindo a base de identidades autocentradas, e propõe descoisificar a 
realidade, "fazer delirar o verbo" (BARROS, 2010), assinalando a busca pelo originário: é a poesia da desconstrução e do desmascaramento. Remete-nos à desutilidade, ao desaprender, à (des)invenção da realidade instituída para construir significados outros, de modo a possibilitar interpretações e gestos de leitura distintos do habitual (uno, longínquo e separado). Nesse sentido, o artivismo de Conka está ligado à ontogênese e refrata o dinamismo social, a complexidade das situações cotidianas e presentes.

Com a funkeira MC Carol, a rapper Conka gravou a música $100 \%$ feminista, que apresenta a luta das mulheres a partir de uma estética subversiva em oposição à estética hegemônica. Na música, as mulheres assumem os lugares de enunciação (ZOPPI-SANTANA, 2017) dos dizeres ${ }^{9}$, para falarem o que não se quer ouvir, o proibido, numa dimensão políticoideológica e sexual:

Represento Dandara e Xica da Silva

Sou mulher, sou negra, meu cabelo é duro

Forte, autoritária

E às vezes frágil, eu assumo

Minha fragilidade não diminui minha força

Eu que mando nessa porra

Eu não vou lavar a louça

Sou mulher independente não aceito opressão.

Faz-se alusão às personalidades Dandara e Xica da Silva, mulheres negras que sofreram pela opressão masculina e branca, mas que contestaram os sistema cultural e político hegemônicos. Trata-se de um recurso à memória para instar a polifonia de vozes e a heterogeneidade de posições, já que os lugares de origem de cada uma dessas mulheres, apesar de suas peculiaridades, mantêm uma comunidade de opressões. O cabelo crespo é ressignificado, passando de desvio negativo de um padrão social de beleza a indicativo de força e autoridade, como signo de origem e ancestralidade. Há, também, a rejeição à divisão habitual de trabalho. A mulher deixa de se identificar com o papel de "secretária do lar" e toma os rumos da história, protagoniza e forma opinião, torna-se agente de sua vida, transpondo a relação

\footnotetext{
9 "Os lugares de enunciação, por presença ou ausência, configuram um modo de dizer (sua circulação, sua legitimidade, sua organização enunciativa) e são diretamente afetados pelos processos históricos de silenciamento. Esses modos de dizer mobilizam as formas discursivas de um eu ou um nós, de cuja representação imaginária a enunciação retira sua legitimidade e força performativa. É a partir desses lugares de enunciação, considerados como uma dimensão das posições-sujeito e, portanto, do processo de constituição do sujeito do discurso, que se instauram as demandas políticas por reconhecimento e as práticas discursivas de resistência" (ZOPPINSANTANA, 2017).
} 
sujeito-objeto pela diferença e pela insistente alteridade, isto é, pela real de sua existência que não se pode desconsiderar.

Karol Conka aborda, também, a autoestima feminina, a independência da mulher em sua vida social, o prazer feminino, a sexualidade. Tais temáticas estão presentes na música Gandaia, em que retrata uma noite festiva. Destaca-se, nessa canção, a postura ativa e emancipada de uma mulher em relação a um assédio sofrido. Desloca-se, assim, a relação passiva estruturada pela cultura hegemônica. A mulher rompe com a passividade de ser o objeto do assédio e de estar em contínuo silêncio, para denunciar o assédio em postura ativa, irrompendo com a construção das identidades femininas passivas e fragilizadas. A mulher é agente de linguagem e não objeto passivo de poder:

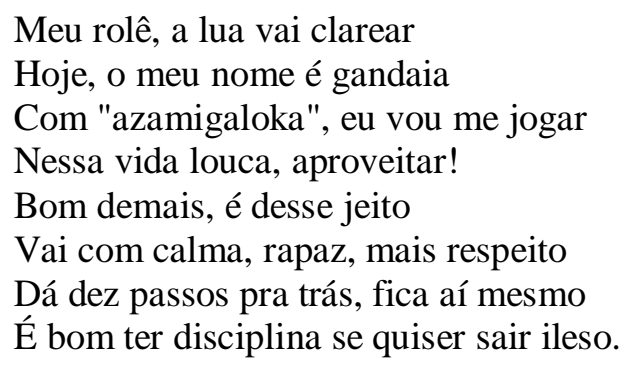

É deposta a identidade fixa de mulher prendada e "honesta", casta e passível de cortejo e admiração por sua suposta pureza. A mulher significa-se como dona de si, de sua sexualidade e de seu modo de ser, o que contracena com o deslocamento das expectativas machistas que a leem como popular e vulgar. A mulher é definitiva de suas decisões. Insere-se em tribos de liberdade, o que flexibiliza a díade socialização-socialidade, a partir do exercício capaz e emancipado da vontade feminina, na construção da alteridade e do cuidado de si, para usar uma expressão foucaultiana (1985).

Na música Tombei, o sujeito-mulher protagoniza o lugar de enunciação. Para Conka (2016), “Tombar é ser feliz. Se sentir realizado de uma maneira simples e prática”. Sobre as mulheres da geração tombamento, explica Karol Conka, "É uma galera que não quer mais saber de opressão e que está cansada de julgamentos e rótulos” (2016). Tombar significa rejeitar as construções de gênero e sexuais como naturais, contrapor o discurso de normatização a partir de estéticas subversivas; rupturas de sentidos para a construção de corpos não padronizados. Tombar vale como aterrorizar as normas e padrões impostos e pressupostos como naturais. “Acontece que a ideia aqui é se expressar livre das repressões, exercendo o direito sobre o 
próprio corpo. O termo "tombar", cuja flexão efetuada foi “tombei”, equivale a lacrar, arrasar e envolve vaidade, aceitação social e empoderamento" (FEILER, 2016).

\author{
Baguncei a divisão, esparramei \\ Peguei sua opinião, 1-2 pisei \\ Se der palpitação, não dá nada, conta até três \\ Se quiser conferir, vem cá, pra ver se aguenta \\ Miro muito bem, enquanto você tenta \\ Enquanto Mamacita fala, vagabundo senta \\ Mamacita fala, vagabundo senta
}

Tombar é delirar a carne, fazer-se verbo, mas também tornar-se silêncio-de-si, resistir à Identidade. Rasgar os rótulos, desconstruir o moralismo judaico-cristão da sociedade ocidental que reduz nossa capacidade de enxergar as coisas de maneira multilógica, conforme Maffesoli (1998; 2004), polissêmica e complexa. Tombar contempla o reconhecimento do espaço (entrelugar) das contradições. A mulher irrompe como discurso, assume papel de fala, sequestra o signo e define o sentido; enquanto fala, não é ignorada; impõe ser ouvida, agride a ordem das palavras, questiona e afronta a ordem do discurso e seus procedimentos de rarefação e exclusão.

A figura de Mamacita é o presentar-se que apresenta e representa as mulheres negras, feministas, emancipadas e politicamente engajadas. Mamacita é prática e discurso, é palavra, mas coerção. Para a compreensão dos fenômenos sociais na atualidade, é preciso mudar a perspectiva: não mais criticar, explicar, mas compreender, admitir [...] além das representações, filosóficas e políticas, cuja saturação é evidente, é preciso apresentar fenomenologicamente o que acontece" (MAFFESOLI, 2004, p. 19). As coisas, sujeitos e seres se apresentam e se presentam num movimento que se sobressai à riqueza, ao dinamismo e à vitalidade deste "mundo-aí".

A apresentação das mulheres negras, em Conka, abala os lugares estanques de enunciação, antes inacessíveis às dissidências sociais e sexuais, isto é, às mulheres, negras, transviadas, periféricas, bissexuais, trans, etc. Esse abalo acontece quando as mulheres, Mamacitas, avançam nas relações sociais e minam as hierarquias, engajando-se na resistência. Esse avanço, que não é permitido, mas conquistado, não ocorre à revelia dos procedimentos e tecnologias de dominação e de si. Muito pelo contrário, ocorre no interior das microrrelações, no cerne do poder mediado pela palavra ativa. Nas palavras de Linn da Quebrada: 
Na quebrada, o funk é poesia. O rap é poesia e é história. As nossas histórias, geralmente, não são contadas. As nossas histórias não são validadas. Nossos corpos não têm peso, não valem a pena. Como então a gente veicula a nossa história? A gente produz memória para falar sobre nós. Como nós produzimos o saber preto? Como a gente não tem tanta possibilidade de fazer livros de história, a gente faz isso na música, a gente faz isso nas paredes da cidade, nos pichos, a gente faz isso pela oralidade, construindo linguagem da nossa forma. Eu acho que esse é um movimento que tem acontecido hoje. Por isso, as identidades, e essa temática tem aparecido e estão vindo à tona. (Grifos nossos) (DE TROI, 2018, p. 5-6).

As tecnologias de dominação, conforme Foucault (2006), são técnicas que agem sobre os sujeitos, disciplinando-os, que docilizam os corpos, definem e frustram desejos, emoções. São as técnicas "[...] que permitem determinar as condutas dos indivíduos para impor certos fins e objetivos" (FOUCAULT, 2006, p. 4). Operam, assim, a partir de mecanismos que legitimam as mais variadas formas de violência por meio de instituições que têm, no sujeito, seu objeto de conhecimento e de dominação a ser normatizado: igrejas, prisões, hospícios, forças armadas, família, discurso médico, direito, estado etc. O objetivo dessas instituições é a modelagem/controle de atitudes, gestos e comportamentos.

As técnicas de dominação são o ponto de partida para uma tecnologia que age, subrepticiamente, a partir de uma dimensão jogacional da linguagem que conduz a uma "verdade de individualização identitária" (MAFFESOLI, 2004; 2005). Essas técnicas objetivam a individualização para “[...] efetuar, por seus, próprios significados, um certo número de operações sobre seus próprios corpos, suas próprias almas, seus próprios pensamentos, suas próprias condutas, e isso de tal forma a transformá-los, modificá-los" (FOUCAULT, 2006, p. 5). O discurso, como recurso de poder, torna-se mais eficaz que a força.

A seu turno, é por meio das técnicas de si que os sujeitos se "auto" definem, numa interação passivo-ativa. Tais técnicas, embora não sejam inventadas pelos sujeitos, são referências encontradas por eles na cultura hegemônica, as quais moldam seus comportamentos, seus gestos, sua visão de mundo. Diversos relatos de experiências de mulheres negras, furtivamente, deixam escapar indícios e tonalidades destas técnicas de si, como exemplo, a própria Karol Conka se considerar feia e desejar se lavar com água sanitária para ficar branca e bonita, quando jovem.

As técnicas de si funcionam, nesse passo, a partir de uma conformação política e estética dos sujeitos subalternizados, os quais pautam suas expressões com base em valores e práticas hegemônicas, construídas por meio dos regimes de verdades cis-hetero-falo-logocêntricos e 
brancos. Impondo, assim, uma série de obrigações "verdadeiras". Não há como desconsiderar o simbólico como instituidor da referência única. Essa referência, estabelecida por meio das tecnologias de dominação e de si, é o masculino-cis-hétero-branco-burguês, de modo que qualquer diferença é vista como um risco ao padrão hegemônico e por isso deve ser eliminada ${ }^{10}$. Também, nesse sentido, as músicas de Conka são expressões contra-hegemônicas, vez que, enquanto um ethos com-partilhado de emoções (MAFFESOLI, 1999), expressam sentimentos comuns entre pessoas (personas - máscaras) que vivenciam as diferenças rechaçadas pelos valores hegemônicos.

Em É o poder, questionam-se as potências conformadoras das expectativas sociais. As demandas políticas, sexuais e sociais dos sujeitos que estão distantes do essencialismo e da imutabilidade são reinventadas e mudadas em pautas de reexistência. Elias e Scotson (2000) apontam que os estabelecidos temem perder sua hegemonia, a segurança da identidade fixa e do sujeito imutável. É o poder põe em xeque a hegemonia dos "estabelecidos", conforme se depreende do excerto a seguir citado:

É o poder, aceita porque dói menos

De longe falam alto, mas de perto tão pequenos

Se afogam no próprio veneno, tão ingênuos

Se a carapuça serve, falo mesmo

E eu cobro quem me deve

É o poder, o mundo é de quem faz

Realidade assusta todos tão normais

Viu? Falei

Depois não vem dizer que eu não avisei

Assim como outsiders que incomodam, desestruturam a ordem vigente e que reinauguram uma nova lógica e uma nova identidade, as vozes que são agenciadas a partir da poética de Conka são importantes para (des)construção das ideias de mulheres, feminino, sexualidade estabelecidas pela hegemonia. Nesse sentido, comunga Maffesoli com a visão de identificações plurais, ao insistir na tese da saturação do indivíduo e do individualismo modernos: "Cada um de nós desfruta menos de uma identidade estável do que de uma série de identificações por meio das quais expressa as diferentes possibilidades que o caracterizam" (MAFFESOLI, 2004, p. 95). Todavia, a lógica moderna, do sujeito racional, com identidade, do terceiro excluído, conforma-nos “[...] em pensar a pluralidade no seio de um mesmo indivíduo" (MAFFESOLI, 2004, p. 95). Em É o poder, a fala questionadora do sujeito feminino

${ }^{10}$ Fazemos alusão ao conceito de Foucault de racismo de estado (2017). 
zomba dos sujeitos estabelecidos, depõe sua base e ataca suas verdades. A palavra do subalternizado torna-se belicosa e grave, incisiva e decisiva, a palavra é o poder que hipersignifica o feminino e ironiza a hegemonia.

Sociedade em choque, eu vim pra incomodar Aqui o santo é forte, é melhor se acostumar Quem foi que disse que isso aqui não era pra mim

Se equivocou

Fui eu quem criei, vivi, escolhi, me descobri

E agora aqui estou

As estéticas negras, eróticas e feministas são visualizadas como as vibrações em conjunto, sentimentos em comum, afetos e experiências, expressões e emoções vivenciadas por pessoas que fogem aos padrões sociais. Não se pode desprezar que "a estética é uma experiência política que tem total influência sobre nossos afetos" (LINN DA QUEBRADA, 2016) ${ }^{11}$. A sociedade em choque, é a fincada na hegemonia, o choque se torna produtivo e aponta para os futuros possíveis que se antecipam no discurso de reexistência da mulher negra. Como afirmou Linn da Quebrada (2018, p. 3)

[...] algumas vezes, é necessário responder também com terror, responder também com agressividade a essa violência, e ainda mais, colocando o meu corpo como arma, o meu corpo como protesto, manifesto e como pólvora, diante desse sistema que já é violento com a gente cotidianamente.

Entendemos as letras dessas canções como sutil declaração de guerra aos padrões higiênicos de beleza e feminilidade. Consciente desse conjunto de afetos e emoções compartilhadas em conjunto, Conka assevera que "As pessoas precisam aprender a respeitar as outras, a se posicionar. Um artista pode ajudar [...] um adolescente que passa por traumas e baixa autoestima. Ninguém diz como nós, mulheres, devemos nos comportar! Menina se comporta como ela quiser" (2015).

A música Lalá, aborda os tabus do objeto sexualidade (FOUCAULT, 2012): desejos, sexualidade, gozo, prazer feminino, ao tratar do sexo oral em mulheres. A mulher profana o microdispositivo de histerização (FOUCAULT, 2017) que fez do seu corpo e sexualidade um campo experimental do dispositivo de sexualidade:

${ }^{11}$ Extraído da entrevista Ser bixa preta e enviadescer / prazer, eu sou MC Linn da Quebrada, devidamente referenciada na sessão final deste trabalho. 
É inacreditável, eles ficam sem ação

Quando a gente sabe o que quer e já mete a pressão

Tem que saber fazer senão gera contradição

Direitos de prazer iguais, mais compreensão

Isso daqui não tá de enfeite

Dá um jeito, se ajeite

Sem ser fake, então vai se deite

Se eu quero, respeite

A problemática do tema advém do imaginário machista que visualiza a mulher não como sujeito de prazer, mas como objeto de prazer do homem. Logo, ela não estaria legitimada a falar do sexo ou a ter suas expectativas de prazer atendidas. Conforme Foucault (2017), através da pedagogia, da medicina e da economia, fez-se do sexo um negócio de Estado, uma questão em que todo corpo social foi convocado a pôr-se em vigilância. Ao sexo passou-se, então, a incumbir a responsabilidade biológica em relação à espécie. Daí o projeto médico, mas também político, de administrar uma gestão estatal do sexo, de modo a produzir uma sexualidade sadia, livre de anomalias. À mulher coube a função (cívica) de gerar e criar filhos saudáveis, tendo sua sexualidade desprovida de qualquer relação com o gozo ou os prazeres:

Esse lance do sexo oral sempre me irritou. Por que a gente sempre faz e o homem não quer fazer ou, quando faz, sai tudo errado? Aquela língua de liquidificador, toda crespa, barba pinicando. É uma região sensível! Quando vai com a mão, parece que tá tocando a campainha 100 vezes. O que me anima é a habilidade na lambida, a malícia e muita saliva. (CONKA, 2017a)

Resultante do monopólio da estrutura política, a violência totalitária - expressa por meio do Estado, deus, família, religião, epistemologias, ontologia etc. - planifica, homogeneíza e monopoliza, para domesticar as emoções, o gozo, os prazeres, as paixões, sob a tentativa de fundamentar e justificar a fictícia ideia de identidades fixas e naturais. Lalá comparece para resistir à castração do gozo, à amputação dos prazeres, à eliminação dos desejos da mulher. O sexo desnuda-se em suas palavras. Resistência ao enclausuramento do corpo, à higienização do sexo. Corpo materializado nas imundícies profanadas pelo gozo. Corpo que epifaniza-se aqui e agora. Em resposta à violência e dominação, as resistências/existências visam impedir a domesticação dos corpos, nos termos de Maffesoli (2004, p. 34)

É contra a 'violência totalitária' deste universalismo que vem ressurgindo o que denominei sabedoria demoníaca. Sabedoria incorporada, mais vivida que 
pensada, que é essencialmente relativista. Vale dizer: que relaciona todos os elementos constitutivos da natureza, inclusive os mais selvagens.

O artivismo, em Conka, toma parte na "sabedoria demoníaca", ressignificada e produtiva, do aqui e do agora. Está posta a duplicidade destruição/reconstrução, “[...] que mantêm uma estreita conexão entre si, constituindo um vaivém incessante entre ordem e desordem, fundamento da estruturação social. Essa, precisa ser ritualizada para se integrar harmoniosamente; se for reprimida ou negada, explode em crueldade" (TEIXEIRA; PORTO, 1998, p. 59). A poética de Conka funda-se em terrenos de reexistência consistindo "[...] em alterar a ordem das letras, para 'derrubar a ordem divina, com objetivos diabólicos, e estabelece: em seu lugar uma desordem infernal'. Esta deformação mágica das palavras é paradigmática" (MAFFESOLI, 2004, p. 34).

Esse totalitarismo ontológico (ser, deus, perfeição) não consegue se afirmar por muito tempo: “A imperfeição é a expressão de um mal, mas de um mal dinâmico. Não devemos esquecer que Eros, esta grande figura emblemática, é, antes de tudo, instigador de inquietação" (MAFFESOLI, 2004, p. 63). Isso porque, o dado mundano é indivisível, assim, enquanto estrutura antropológica, a violência é um exemplo de que "Em todas as coisas existe um misto de atração-repulsa, amor-ódio, generosidade e egoísmo. Basta olhar um pouco mais de perto para constatar que os sentimentos mais elevados são permeados de seu contrário" (MAFFESOLI, 2004, p. 62).

$\mathrm{O}$ artivismo, em Karol Conka, portanto, desnuda-se como resistência, existência e reexistência, via (est)ética de identificações, de personas em condição inevitável de imersão no cotidiano, dinamismo social, que vivenciam o incômodo de suas possibilidades mais extremas. Há, assim, nesse movimento, uma recusa absoluta aos valores hegemônicos, uma luta contra a moral preestabelecida que tenta castrar o querer-viver, o estar-junto, o aqui e agora, o compartilhar em conjunto outros valores que não os oficiais. As canções analisadas tomam partido no desenvolvimento de uma ética tribal não essencialista, a partir de identidades fragmentadas, decaídas, em ruínas que afirmam que “"não somos” o que a sociedade e o Estado, cada um à sua forma, nos atribui, mas 'queremos ser diferentes' do que nos foi atribuído ou nos é oferecido como meio único de adquirir a igualdade”. (MISKOLCI, 2010, p. 3).

Karol Conka, a partir desse tribalismo estético, agencia, em sua discursividade rapper, uma metanóia, que pensa sempre ao lado, que (co)memora. A tônica de sua lírica é a seguinte: o retorno do conflito é inevitável. Mesmo que isso soe como angustiante por denunciar o vazio, 
a falta, o trágico, é nesse ciclo, todavia, que toda criação é possível. A angústia não pode ser ignorada, “E isto porque ela é, stricto sensu, 'intuição do vazio'. Vazio que não é a mesma coisa que nada, mas, antes, condição de possibilidade do que está por nascer” (MAFFESOLI, 2004, p. 74). O vazio, a falta, o trágico, devem ser vividos, comemorados, sentidos.

A carne se faz verbo e canta a resistência pelo artivismo negro e feminista. O verbo delira para presentar-se enquanto carne. A carne é a condição fundamental de cada um, logo é inacessível ao conhecimento meramente teórico, e ao raciocínio calculante. A carne é pagã, popular, vulgar, carnavalizada e erótica. O corpo é político, discursivo, lido como texto inscrito, escrito e reescrito, como trabalho de linguagem. A carne profana o corpo e pluraliza histórias e saberes, é nosso contra-ataque ao autoritarismo da história única (ADICHIE, 2009). A vida penetra na língua e a língua torna-se atitude e compromisso com mudança. A palavra destrói, desconstrói, reconstrói para construir. A mulher negra rapper sequestra a fala e decide o sentido, faz frente ao antagonismo social que comparece na palavra para assujeitar. É um ponto de partida anterior à compreensão/interpretação, da ordem do sentir. É um ponto de partida em direção às inúmeras possibilidades de ultrapassagem da realidade dada na direção da(s) possibilidade(s) mais íntimas do si e do outro. Conka é uma voz dialógica que ecoa com outras, com vistas à democratização do discurso, ao fortalecimento de laços de ancestralidade e à (res)significância de si e do outro/Outro.

\section{Considerações finais}

É conveniente mencionar que a poética de Karol Conka reúne um conjunto de afetos, sentimentos, emoções agenciados em sua estética negra, feminista, erótica, emancipada, que não aceita o lugar de passividade e objetificação dado pelos valores hegemônicos. Assim, sustenta-se que a poesia contra-canônica de Conka remete-nos à desutilidade, ao desaprender, ao desinventar a realidade instituída para construir significados outros, de modo a possibilitar outras interpretações além da interpretação mais habitual. Está evidenciado o perfil artivista de suas composições.

Nesse contexto, as canções da rapper são expressões e experiências de existência, reexistência e resistência à docilização dos corpos, ao triunfo da referência única, como expressão de uma contra-ideologia dos corpos, da sexualidade e das diferenças. Mamacita fala, vagabundo senta! O ativismo musical de Karol Conka resiste à "verdade do verdadeiro sexo". O desejo contradiz o racionalismo extremo; deleita-se com a sensibilidade, a partir de uma ética 
da estética, uma compreensão afetiva do mundo, numa postura de contemplação, de existência e resistência, que aponta para outras reexistências e alteridades subalternizadas, desnudando e minando hierarquias e opressões, colonialidades e hegemonias. 


\section{Referências}

ABBAGNANO, Nicola. Dicionário de filosofia. São Paulo: Martins Fontes, 2007.

ADICHIE, Chimamanda. O perigo de uma única história. Tradução de Eri a Barbosa. Original disponível em: http://www. ted. com/tal s/lang/ptbr/chimamanda_adichie_the_danger_of_a_single_story. html. s/d. Tradução disponível em: http://www. google. pt/url, 2009.

AUROUX, Sylvain. A questão da origem das línguas, seguido de A historicidade das ciências. Campinas/SP: RG, 2008.

BAIGORRI, Laura - Recapitulando: modelos de artivismo (1994-2003), (Setembro 2003), Acesso em: 23 abril 2019.2 Disponível <http://www.uoc.edu/artnodes/esp/art/baigorri0803/baigorri0803.html>.

BAKHTIN, M (V.N. Volochinov). Marxismo e filosofia da linguagem. Tradução de Michel Lauch e Iara Frateschi Vieira. 6.ed. São Paulo: Editora Huritec 1992.

BARROS, Manoel de. Poesia completa. São Paulo: Leya, 2010.

BENTES, Ivana. O que pode um funk? Revista Cult, São Paulo, 20 dez. 2017. Disponível em:<https://revistacult.uol.com.br/home/anitta-vai-malandra-ivana-bentes/> Acesso em: 22 dez. 2017.

BHABHA, Homi K. O local da cultura. 2.ed. Belo Horizonte: Ed. UFMG, 2013.

BOBBIO, Norberto. A era dos direitos. Tradução de Carlos Nelson Coutinho. Rio de Janeiro, 2004.

CONKA, Karol. Karol Conka fala de racismo em caso da banda Fly: "Passei minha vida inteira sendo xingada". Papel Pop, [S.l.], 06 out. 2015. Entrevista concedida a Pedro Rocha. Disponível em: $<$ http://www.papelpop.com/2015/10/karol-conka-fala-de-racismo-em-caso-dabanda-fly-passei-minha-vida-inteira-sendo-xingada/> Acesso em: 27 nov. 2017.

CONKA, Karol. Karol Conka fala sobre feminismo e racismo: 'Preconceito machuca'. O Globo, Rio de Janeiro, 09 set.. 2016. Entrevista concedida a Kelly Krishna Rios. Disponível em:<https://oglobo.globo.com/ela/moda/karol-conka-fala-sobre-feminismo-racismopreconceito-machuca-20042189\#ixzz55cReuvjf> Acesso em: 9 out. 2018.

CONKA, Karol. Karol Conka rima sobre sexo oral no single "Lalá". Rollingstone, [S.l.], 08 jun. 2017a. Entrevista concedida a Redação do RollingStone. Disponível em: $<$ http://rollingstone.uol.com.br/noticia/karol-conka-rima-sobre-sexo-oral-single-lalaassista-videoclipe/\#imagem0> Acesso em 18 dez. 2017.

CONKA, Karol.Voz ativa contra o preconceito, Karol Conka assume o comando do 'Superbonita' e finaliza novo disco. O Globo, Rio de Janeiro, 19 jan. 2017. Entrevista concedida a Luccas Oliveira. Disponível em: <https://oglobo.globo.com/cultura/musica/voz-ativa-contrapreconceito-karol-conka-assume-comando-do-superbonita-finaliza-novo-disco-20795555> Acesso em: $\quad 92$ out. 2018.2 Disponível em: $<$ http://www.scielo.br/scielo.php?script=sci_arttext\&pid=S0104$44782010000200006 \& \operatorname{lng}=\mathrm{en} \& n r m=i s o>$. Acesso em 29 jan. 2018. 
DE TROI, Marcelo. Obra das Travas-Entrevista com a artista Linn da Quebrada. Revista Periódicus, v. 1, n. 10, p. 446-457, 2018.

ELIAS, Norbert; e SCOTSON, John. L.; Os estabelecidos e os outsiders: sociologia das relações de poder a partir de uma comunidade. Rio de Janeiro: Jorge Zahar Editor, 2000.

FEILER, Camila.. 3 lições que Karol Conká nos ensinou. Terra, [S.l], 16 nov. 2016. Disponível em:<http://eoh.com.br/3-licoes-que-karol-conka-nos-ensinou/> Acesso em: 19 out. 2017.

FEYERABEND, Paul K. Contra o método. [S.l.] Relógio D'Água; Ciência, 2007.

FOUCAULT, Michel. A ordem do discurso: aula inaugural no Collège de France, pronunciada em 2 de dezembro de 1970. Tradução de Laura Fraga de Almeida Sampaio. São Paulo: Edições Loyola, 2012.

FOUCAULT, Michel. Ética, Sexualidade, Política. 2.ed. (Coleção Ditos e.Escritos V). Rio de Janeiro: Forense Universitária, 2006.

FOUCAULT, Michel. História da sexualidade: a vontade de saber. Rio de Janeiro: Graal, v. 1, 2017.

FOUCAULT, Michel. História da sexualidade: o cuidado de si. Rio de Janeiro: Graal, v. 3, 1985.

FRASER, Nancy; HONNETH, Axel. ¿Redistribución o reconocimiento?: un debate políticofilosófico. [S.L]: Fundación Paideia Galiza, 2006.

Guerreiras Do Rap. Direção: Tiago Bambine, Pedro Caldas e Ivan Vale Ferreria. [S.1.]: 13 Produções, 2002 (6min).

HALL, Stuart. A identidade cultural na pós-modernidade. 9. ed. Rio de Janeiro: DP \& A, 2004.

LINN DA QUEBRADA. Ser bixa preta e enviadescer / prazer, eu sou MC Linn da Quebrada. Canal youtube Regina Volpato, [S.l], 06 set. 2016. Entrevista concedida a Regina Volpato. Disponível em:<https://www.youtube.com/watch?v=jBEKL9lnYGA> Acesso em: 25 nov. 2017.

MAFFESOLI, Michel. A parte do diabo: resumo da subversão pós-moderna. Rio de Janeiro: Record, 2004.

MAFFESOLI, Michel. A Violência Totalitária: Ensaio de Antropologia Política. Porto Alegre: Sulina, 2001.

MAFFESOLI, Michel. Elogio da razão sensível. Petrópolis: Vozes, 1998.

MAFFESOLI, Michel. No Fundo das Aparências. Petrópolis, RJ: Vozes, 1999.

MAFFESOLI, Michel. O Conhecimento Comum. São Paulo: Brasiliense, 1988.

MAFFESOLI, Michel. O mistério da conjunção: ensaios sobre comunicação, corpo e socialidade. Porto Alegre: Sulina, 2005.

MAFFESOLI, Michel. O Tempo das Tribos: O Declínio do Individualismo nas Sociedades de Massa. Rio de Janeiro: Forense Universitária, 2010. 
MAFFESOLI, Michel. Saturação. São Paulo: Iluminuras, 2010.

MATOS, Marlise. Movimento e teoria feminista: é possível reconstruir a teoria feminista a partir do Sul global?. Rev. Sociol. Polit., Curitiba , v. 18, n. 36, p. 67-92, 2010.

MIGNOLO, Walter D. Histórias locais/Projetos globais. Colonialidade, saberes subalternos e pensamento liminar. Belo Horizonte: UFMG, 2003.

MISKOLCI, Richard. Não somos, queremos: notas sobre o declínio do essencialismo estratégico. Salvador, 17 set. 2010. Disponível em: <http://www.ufscar.br/cis/wpcontent/uploads/N\%C3\%A3o-Somos-queremosRichardMiskolci.pdf $>$. Acesso em: 20 jan. 2018.

ORLANDI, Eni Pulcinelli. As formas do silêncio: no movimento dos sentidos. 2. ed. Campinas: Ed.UNICAMP, 1993.

ORLANDI, Eni Pulcinelli. Discurso fundador: (a formação do país e a construção da identidade nacional). Campinas, SP: Pontes, 1993.

QUIJANO, Aníbal. Colonialidade do poder, eurocentrismo e América Latina. In: LANDER, Edgardo (Org.). A colonialidade do saber: eurocentrismo e ciências sociais. Perspectivas latino-americanas. Buenos Aires: Clacso, 2005.

RIBEIRO, Djamila. Feminismo negro: violências históricas e simbólicas. Geledés, São Paulo, 18 ago. 2015. Disponível em:<https://www.geledes.org.br/feminismo-negro-violenciashistoricas-e-simbolicas/> Acesso em: 08 jan. 2018.

SAFATLE, V. Erotismo, sexualidade e gênero. Curso ministrado por Vladimir Safatle, São Paulo, 2014. Disponível em:<http://www.academia.edu/8674660/Curso_Integral__Erotismo_sexualidade_e_gênero_sobre_Bataille_Foucault_e_Judith_Butler_-_2014> Acesso em: 29 jan. 2018.

TEIXEIRA, Maria Cecília Sanches; PORTO, Maria do Rosário Silveira. Violência, insegurança e imaginário do medo. Cad. CEDES, Campinas, v. 19, n. 47, p. 51-66, 1998.

What Happened, Miss Simone? Direção de Liz Garbus. [S.l.]: Netflix, 2015 (102min).

ZOPPI-FONTANA, Mónica. "Lugar de fala": enunciação, subjetivação, resistência. Revista Conexão Letras, [S.l.], v. 12, n. 18, jan. 2018. ISSN 1980-332x. Disponível em: <http://seer.ufrgs.br/index.php/conexaoletras/article/view/79457/46458>. Acesso em: 29 jan. 2018. 